\title{
Discrimination learning with an avoidance procedure*
}

\author{
SEWARD A. MOOT, LEONARD P. OVERBY, and ROBERT C. BOLLES \\ Liniversity of it'ashington, Seattle. Washington 98105
}

\begin{abstract}
Groups of rats were trained in a T-maze to go to the white arm to avoid shock. Avoidance performance and discrimination learning were markedly improved by pretraining with a few (up to 25) trials in which the rats were forced to run to the white arm.
\end{abstract}

The avoidance literature contains remarkably few cases of discrimination learning of the type where the animal can avoid shock by running into a white compartment. but not by running into a black one. The few reported studies that have used such a procedure have typically found either no black-white discrimination or no avoidance. i.e.. the discriminated response does not occur quickly enough to avoid shock (e.g.. Caul \& Barrett. 1973). In some laboratories, discrimination procedures have been used routinely, but little information is provided about how successful the discrimination is or what techniques are used to produce it (e.g. . Horel. Bettinger, Royce, \& Meyer, 1966).

The multitude of studies that are commonly called "discriminated avoidance" tvpically make the avoidance of shock contingent upon the animal's responding appropriately in the presence of the CS, but provide no penalty for responding in the absence of the CS. One study which imposed such a discrimination condition (Coppock \& Mowrer, 1947). found very poor avoidance performance. In investigating avoidance discrimination in our laboratory, we discovered that: (a) conventional training procedures produced poor performance: (b) variation in the conventional parameters such as shock intensity, temporal intervals, and the response required of $\mathrm{S}$ failed to improve performance; but that (c) there was a procedural technique which did greatly facilitate avoidance discrimination. The purpose of the present paper is to describe this technique.

\section{METHOD}

\section{Subjects}

The animals were 27 naive male rats of Long-Evans descent, approximately 100 days old.

\footnotetext{
Apparatus

The Ss were trained in a T-maze wich had a black startbox and stem and arms into which could be fitted black and white plastic inserts. The inserts were constructed so that, when in place, they divided the end of the stem or choice area vertically in to black and white areas which could be seen from the startbox. The startbox measured $16 \times 10 \times 14 \mathrm{~cm}$ high: the stem. $24 \times 10 \times$ $14 \mathrm{~cm}$; each arm, $30 \times 10 \times 14 \mathrm{~cm}$. The grid floor was made of

*This study was supported by Research Grant GB-20801 from the National Science Foundation. Reprints should be requested from R. C. Bolles, Department of Psychology, University of Washing ton, Seattle, Washington 98105 .
}

$0.7-\mathrm{cm}$ stainless steel rods spaced on $2.5-\mathrm{cm}$ centers, which were wired so that shock could be delivered in the startbox, stem, and either arm. The shock was $0.5 \mathrm{~mA}$ and scrambled. The startbox door served as the CS.

\section{Procedure}

The Ss were randomly assigned nine to a group. They received differential treatment only in pretraining: the discrimination training itself was identical for all Ss. In pretraining, the three groups were given 5,15 , or 25 trials, all of which were forced to the white arm by blocking off the black arm. In pretraining, $S$ was placed in the startbox, and after $5 \mathrm{sec}$, the trial was begun by opening the door. The Ss could avoid shock by running to the white arm in $10 \mathrm{sec}$ : after $10 \mathrm{sec}$, shock was applied to the startbox and stem floor and $\mathrm{S}$ was required to escape by running into the white arm. Which side was white on a given trial was determined by a Gellerman series. All pretraining trials were run in one session with a 120 -sec intertrial interval. To summarize. the groups differed in the number $(5,15$, or 25$)$ of trials in which they were forced to avoid or escape by running to the safe (white) part of the T-maze.

On the day following pretraining, all Ss were trained on the discrimination task. The conditions, were the same as in pretraining, except that all trials were free, so that $S$ could run either to the black arm (which was counted as an error) or to the white arm (white was correct for all Ss). If $\mathrm{S}$ made an error in less than $10 \mathrm{sec}$, i.e., an avoidance error, shock was delivered immediately and continued until $\mathrm{S}$ entered the correct side. All Ss were trained in a single 40-trial session.

\section{RESULTS AND DISCUSSION}

The group which received 25 pretraining trials performed well: seven of the nine Ss met a criterion of eight consecutive correct avoidances, and the median $\mathrm{S}$ met this criterion by Trial 15 . During the 40-trial training session, these Ss averaged $71 \%$ correct avoidances, and counting all trials, $82 \%$ of runs were to the white arm. In other words, the 25-trial pretraining group showed rapid acquisition of avoidance running and very good discrimination performance. By contrast. the group receiving only five pretraining trials performed poorly: none of these Ss met the criterion of eight consecutive correct avoidances, and the group as a whole made correct avoidances on only $40 \%$ of the trials, and made only $50 \%$ of their runs to the white arm. In short, this group evidenced relatively poor avoidance behavior and no discrimination learning. The intermediate group, with 15 pretraining trials, gave intermediate performance: two Ss met the criterion of learning. the mean percentage of avoidances was $50 \%$, and the 
percentage of runs to the white arm was $78 \%$. Overall $\mathrm{F}$ tests of the differences among groups were highly reliable $(p<.01)$ for all these response measures (nonlearners were assigned a trial score of 40 ).

An analysis of errors during discrimination training indicated that the bulk of them $(88 \%$ for the 5 -trial group) were perseverative. i.e., these Ss ran to that side which was safe on the preceding trial. This percentage dropped to $30 \%$ for the 15-trial group, which suggests that one effect of the pretraining experience was simply to weaken the rat's initially strong tendency to run perseveratively. This effect was evidently achieved within 15 pretraining trials. The greater superiority in discrimination performance of the 25-trial group appears to illustrate the operation of another mechanism. The data suggest that these Ss were learning the safety value of white. i.e., they were learning that white was safe, and they therefore went into discrimination training with the appropriate cue already established as a safety signal. In summary. in the first few pretraining trials. S appeared to learn not to respond to one possible cue, viz, the location of the previously safe area, and then, within about 25 pretraining trials, $\mathrm{S}$ began to learn what cue it should respond to.

\section{REFERENCES}

Caul, W. F., \& Barrett, R. J. Shuttle-box versus Y-maze avoidance: Value of multiple response measures in interpreting active-avoidance performance of rats. Journal of Comparative \& Physiological Psychology, 1973, 84, 572-578.

Coppock, H. W., \& Mowrer, O. H. Inter-trial responses as "rehearsal": A study of "overt thinking" in animals. A merican Journal of Psychology, 1947, 60,608-616.

Horel, J. A., Bettinger, L. A., Royce, G. J., \& Mever, D. R. Role of neocortex in the learning and relearning of two visual habits by the rat. Journal of Comparative \& Physiological Psychology, 1966, 61, 66-78.

(Received for publication November 19, 1973.) 